\title{
Should we use spirometry in the early detection of COPD?
}

\section{To the Editors:}

ENRIGHT et al. [1] in the European Respiratory Monograph, promote office spirometry as the way forward in the routine assessment of asthma and chronic obstructive pulmonary disease (COPD), and in the early detection of COPD. They define office spirometry as 'spirometry performed in the primary care setting'. There is an unwelcome ambiguity in their paper when it comes to both of these subjects, and the evidence they use to support their arguments is far from decisive. In the case of the early detection of COPD, the evidence seems to oppose their position.

My first concern is about their use of the term office spirometry, which seems to imply spirometry carried out by the consulting clinician. They say that spirometry with electronic spirometers is now faster than it was with traditional bellows spirometers. This latter suggestion is untrue, even using the $6 \mathrm{~s}$ manoeuvre, since the spirometry manoeuvre is independent of the type of spirometer used, the learning curve for the patient is the same and the instruction given by the operator is also identical. They believe that the main problem with office spirometry is in the quality of the instruction and supervision of the test by the clinician. I agree and think that this must be one of the main objections to spirometry being conducted by clinicians during routine consultations. They quote a primary care Dutch study in which the quality of the spirometry was unacceptably variable [2]. Furthermore, they recommend certification for nurses and technologists carrying out spirometry in primary care. This hardly encourages the routine office use of spirometry by clinicians in their consultations.

The main argument put forward by ENRIGHT et al. [1] is for the use of spirometry in the early detection of COPD. They say that spirometry fulfils all the standard criteria for application of a medical test for screening. A fundamental criterion for any screening programme is the availability of a useful intervention for the patient who screens positive [3]. The main reason to detect COPD in its early stages is to intervene with smoking cessation. ENRIGHT et al. [1] quote three papers in support of the role of early diagnosis of COPD in smoking cessation. None of these actually support their assertion.

The first by RisSER et al. [4] is a trial of a complex intervention comparing education and a motivational intervention with education alone, in which spirometry was a just component of the motivational intervention. In the second paper SEGNAN et al. [5] actually conclude, "In no treatment group was the outcome significantly different from that for one-time counselling at the $(\mathrm{p}<0.05)$ level." In the third paper, GORECKA et al. [6] demonstrated that the diagnosis of airflow limitation had no effect in improving smoking cessation overall, and only in a subanalysis could they show that it leads to an improvement in smoking cessation in those who have moderate or severe airflow limitation. The Global Initiative for Chronic Obstructive Lung Disease (GOLD) guidelines acknowledge the uncertainty surrounding the benefits of community screening of COPD [7]. While there is no argument that smokers should be sought and helped to quit smoking, there is no evidence that early diagnosis of COPD improves smoking cessation.

The promotion of early diagnosis of COPD has been gathering momentum despite the lack of evidence to justify it. Many papers are appearing which report the efforts of clinicians to diagnose COPD early. In the Differential Diagnosis between Asthma and COPD study, BUFFELS et al. [8] report that spirometry-based screening for COPD in primary care doubles the rate of diagnosis of COPD.

The impact on patients and services of a policy to diagnose chronic obstructive pulmonary disease early, which doubles the number of cases in the system, is likely to be expensive and will dilute the resources available for the management of symptomatic chronic obstructive pulmonary disease. It should not even be considered until there is at least some evidence to support it.

\section{P. White}

Dept of General Practice and Primary Care, Guy's, King's and St Thomas' School of Medicine, King's College, London, UK.

\section{REFERENCES}

1 Enright PL, Studnicka M, Zielinski J. Spirometry to detect and manage chronic obstructive pulmonary disease and asthma in the primary care setting. In: Wouters EF, Gosselink R, Stam H, eds. Lung Function Testing. Eur Respir Mon 2005; 31: 1-14.

2 Schermer TR, Jacobs JE, Chavannes NH, et al. Validity of spirometric testing in a general practice population of patients with chronic obstructive pulmonary disease (COPD). Thorax 2003; 58: 861-866.

3 Wilson JM. Principles of screening for disease. Proc $R$ Soc Med 1971; 64: 1255-1256.

4 Risser NL, Belcher DW. Adding spirometry, carbon monoxide, and pulmonary symptom results to smoking cessation counseling: a randomized trial. J Gen Intern Med 1990; 5: 16-22.

5 Segnan N, Ponti A, Battista RN, et al. A randomized trial of smoking cessation interventions in general practice in Italy. Cancer Causes Control 1991; 2: 239-246.

6 Gorecka D, Bednarek M, Nowinski A, Puscinska E, GoljanGeremek A, Zielinski J. Diagnosis of airflow limitation combined with smoking cessation advice increases stopsmoking rate. Chest 2003; 123: 1916-1923. 
7 Pauwels RA, Buist AS, Ma P, Jenkins CR, Hurd SS. Global strategy for the diagnosis, management, and prevention of chronic obstructive pulmonary disease: National Heart, Lung, and Blood Institute and World Health Organization Global Initiative for Chronic Obstructive Lung Disease (GOLD): executive summary. Respir Care 2001; 46: 798-82 (2004 update at www.goldcopd.com).

8 Buffels J, Degryse J, Heyrman J, Decramer M. Office spirometry significantly improves early detection of COPD in general practice: the DIDASCO Study. Chest 2004; 125: 1394-1399.

DOI: $10.1183 / 09031936.05 .00061705$

\section{From the authors:}

Pulmonary specialists welcome increased communication and collaborative work with general practitioners in an attempt to find the most effective evidence-based methods to decrease the substantial morbidity and mortality of asthma and chronic obstructive disorder (COPD). In this issue of the European Respiratory Journal, P. White has highlighted one of the gaps in the evidence base for recommending increased utilisation of spirometry by primary care practitioners. The evidence is indeed weak, in that adding spirometry testing to methods already demonstrated to improve smoking cessation rates (such as counselling, nicotine replacement therapy and bupropion) will further improve the success rates. The published studies were either inadequately designed or had inadequate statistical power to answer this important question. However, several medications to halt the progression of COPD will probably become available in the next few years [1], so we should prepare for them by working to make office spirometry more effective in the primary care setting.

I admit that there are few studies which decisively prove that the addition of spirometry, to the history and physical examination of patients with respiratory symptoms, improves the ability of general practitioners to substantially improve patient-centred outcomes [2]. However, 20 yrs ago, the same could have been said of blood pressure measurements, or blood glucose and haemoglobin-A1c measurements for obese and diabetic patients, respectively. I characterise the tone of our chapter in the European Respiratory Monograph [3] as suggesting "cautious optimism." A major goal of our recommendations is to minimise spirometry misclassification rates, which leads to the many caveats in our recommendations.

When using forced expiratory volume in six seconds reference equations, the average spirometry test session (with a range of 3-8 manoeuvres) is indeed shorter, because the end-of-test criterion for an acceptable manoeuvre is much easier to meet (for children and patients with airway obstruction). Therefore, fewer manoeuvres are needed to meet the goal of three acceptable (including two repeatable) manoeuvres.

In our opinion, whoever coaches the patient to perform spirometry tests needs training and performance-based certification. In the UK, this person is usually the general practitioner (a physician), but in the USA, nurses or technologists often perform the testing. Sometimes a nurse practitioner, physician's assistant, or chronic disease manager uses the results to diagnose or manage the patient.

In Tucson, Arizona, USA, I have seen bumper stickers which say "If I had known that I'd live this long, I would have taken better care of myself." You have probably seen hundreds of patients dying from end-stage COPD, first diagnosed when their forced expiratory volume in one second was $<1 \mathrm{~L}[4]$. How many of them have wondered, "Since my lung disease was apparently slowly progressing for decades before I was finally diagnosed, why didn't anyone tell me about it many years ago? I would have tried much harder to quit smoking." I believe that our time and our limited smoking cessation resources should be preferentially targeted towards patients with the highest risks for smoking-related disease.

In conclusion, epidemiological studies have decisively demonstrated that airway obstruction is the second or third most important risk factor for morbidity and mortality in smoking adults.

\section{P. Enright}

College of Public Health, The University of Arizona, Tucson, AZ, USA.

\section{REFERENCES}

1 Barnes PJ, Stockley RA. COPD: current therapeutic interventions and future approaches. Eur Respir J 2005; 25: 1084-1106.

2 Chavannes N, Schermer T, Akkermans R, et al. Impact of spirometry on GP's diagnostic differentiation and decision-making. Respir Med 2004; 98: 1124-1130.

3 Enright PL, Studnicka M, Zielinski J. Spirometry to detect and manage chronic obstructive pulmonary disease and asthma in the primary care setting. In: Gosselink R, Stam H, eds. Lung Function Testing. Eur Respir Mono 2005; 31: 1-14.

4 Zoia MC, Corsico AG, Beccaria M, et al. Exacerbations as a starting point of pro-active COPD management. Respir Med 2005. 